American Journal of Applied Sciences 7 (3): 402-407, 2010

ISSN 1546-9239

(C) 2010Science Publications

\title{
Assessment of Thermal Comfort: A Study at Closed and Ventilated Call Centre
}

\author{
${ }^{1}$ A.R. Ismail, ${ }^{2}$ N. Jusoh, ${ }^{2}$ N.K. Makhtar, ${ }^{2}$ J.S.M. Zakaria, ${ }^{2}$ M.K. Zainudin, \\ ${ }^{2}$ Z.C. Omar and ${ }^{2}$ R.A. Ghani \\ ${ }^{1}$ Faculty of Mechanical Engineering, University Malaysia Pahang, \\ 26600 Pekan, Pahang, Malaysia \\ ${ }^{2}$ Department of Mechanical and Materials Engineering, \\ Faculty of Engineering and Built Environment, \\ University Kebangsaan Malaysia, 43600 UKM Bangi, Malaysia
}

\begin{abstract}
Problem statement: The aims of study were to investigate the effects of environmental factors including the human physiology and thermal comfort during the cycle of process works in workplace. Approach: The selected production line was handling the restoration of trouble report. The environment examined was the relative humidity (\%), wind speed $\left(\mathrm{m} \mathrm{sec}^{-1}\right)$, illuminance (lux) and air temperature $\left({ }^{\circ} \mathrm{C}\right)$ of the surrounding workstation area. The environmental factors were measured using thermal comfort apparatus, which is capable to measure simultaneously those mentioned environmental factors. The time series data of fluctuating level of factors were plotted to identify the significant changes of factors. Then the thermal comfort of the workers was assessed by using ISO Standard 7730 and thermal sensation scale by using Predicted Mean Vote (PMV). Further Predicted Percentage Dissatisfied (PPD) is used to estimate the thermal comfort satisfaction of the occupant. Finally the PMV were plotted to present the thermal comfort scenario of workers involved in related workstation. Results: The thermal comfort assessment of this workplace which is slightly warm following by thermal sensation and likely to be dissatisfied by the occupant. Conclusion: The result indicated that the activity level and clothing more influenced comfort to the occupants.
\end{abstract}

Key words: Thermal, comfort, close, ventilated

\section{INTRODUCTION}

It is a well known fact, that the environmental factors influence the performance of a human being. Thermal stress, high humidity and insufficient illumination are often the reason for the limitation of the ability to fulfill a certain task. But what about the situation, this task is to be fulfilled at a certain company? The limitation of processing this task, is affecting the productivity of the company. If the decrease in productivity is lasting for a longer period and many employees have to deal with these circumstances, the effect to the productivity can be enormous. The loss of each worker will affect the others and add up. The condition of the environment of a company seems to be very important with respect to the productivity and hence the success. A number of studies have found that, Air-conditioned building: This has sealed windows and cooling is available at all times of the year. Space conditions are tightly controlled. In this case low-energy design requires optimization of the HVAC plant, for example minimizing the use of heating and cooling at the same time as fan power consumption. Typically, the air will also be subject to particle filtration and humidity control (Holmes and Hacker, 2007).

The effect of exposure to air-conditioned environments on thermal comfort perception in naturally ventilated buildings in Singapore and Indonesia found for people exposed to air-conditioned spaces for less than $4 \mathrm{~h}$ and for more than $8 \mathrm{~h} \mathrm{day}^{-1}$ showed preferences for higher comfort temperatures (Feriadi et al., 2003). People with less than $4 \mathrm{~h} \mathrm{day}^{-1}$ exposure to air-conditioning, may have been acclimatized to the hot and humid environment (Chun et al., 2008). People with longer exposure time to air-conditioning were thought to desire warmer temperatures after working inside an air-conditioning office all day (Chun et al., 2008). The influence of metabolic changes on thermal sensation was examined

Corresponding Author: A.R. Ismail, Faculty of Mechanical Engineering, University Malaysia Pahang, 26600 UMP Pekan, Pahang, Malaysia 
through modified step-changes during the experiment (Chun et al., 2008). Increased activity and even low metabolic activity, prior to an experiment, affect thermal perceptions and preferences of humans (Goto et al., 2002). When predicting thermal sensation, detailed descriptions of the activity during the past $15 \mathrm{~min}$ improve the precision of the vote predicting. Clothing adjustments are found to be one of the causal links between indoor thermal comfort and outdoor weather. Evidence from a cross-sectional study of clothing in Australia demonstrates that outdoor temperatures strongly influence clothing worn indoors and no correlation was found to prevailing indoor temperatures (Morgan et al., 2002).

Thermal comfort is recognized as a key parameter for a healthy and productive workplace. At the same time, lowering energy use in commercial building is vital if a significant reduction in greenhouse gas emissions is to be achieved. Traditionally thermal comfort has been achieved at the expense of significant energy use for heating and/or cooling. In another major study, Taylor et al. (2008) found that a well-designed building should be able to provide good thermal comfort, while simultaneously having low energy consumption.

Thermal comfort can be defined as that condition of mind which expresses satisfaction with the thermal environment (Ho et al., 2008). The reference to 'mind' indicates that it is essentially a subjective term; however, there has been extensive research in this area and a number of indices exist which can be used to assess environments for thermal comfort (Fanger, 1970; Shek and Chan, 2008). However (Ibrahim et al., 2007) suggested three conditions for comfort; these are that the body is in heat balance and that the mean skin temperature and sweat rate are within limits required for comfort. Conditions required for heat balance can be derived from a heat balance equation. Mean skin temperatures and sweat rates that are acceptable for comfort have been derived from empirical investigation (Holmes and Hacker, 2007).

Predicted Mean Vote (PMV) is a parameter for assessing thermal comfort in an occupied zone based on the conditions of metabolic rate, clothing, air speed besides temperature and humidity. PMV values refer the ASHRAE thermal sensation scale (Holmes and Hacker, 2007) that ranges from -3 to 3 as follows: 3 = hot, 2 = warm, $1=$ slightly warm, $0=$ neutral, -1 = slightly cool, $-2=$ cool, $-3=$ cold. Figure 1 summarizes the overall process of using the six variables associated with thermal comfort sensation to evaluate the PMV (American Society of Heating, 2005). The general comfort equation developed by
Fanger (1970) and Holmes and Hacker (2007) to describe the conditions under which a large group of people will feel in thermal neutrality is too complex and cannot be used in real time applications:

$$
\begin{aligned}
\mathrm{PMV}= & \left(0.028+0.3033 \mathrm{e}^{-0.036 \mathrm{M}}\right)\{(\mathrm{M}-\mathrm{W})-3.05 \\
& {[5.733-0.000699(\mathrm{M}-\mathrm{W})-\mathrm{Pa}] } \\
& -0.42[(\mathrm{M}-\mathrm{W})-58.15]-0.0173 \\
& \mathrm{M}(5.867-\mathrm{Pa})-0.0014 \mathrm{M}\left(34-\mathrm{T}_{\mathrm{a}}\right) \\
& -3.96 \times 10^{-8} \mathrm{fcl}\left[\left(\mathrm{T}_{\mathrm{cl}}+273\right)^{4}-\left(\mathrm{T}_{\mathrm{mrt}}+273\right)^{4}\right] \\
& \left.- \text { fcl.hc }\left(\mathrm{T}_{\mathrm{cl}}-\mathrm{T}_{\mathrm{a}}\right)\right\}
\end{aligned}
$$

Where:

$$
\begin{aligned}
& \mathrm{T}_{\mathrm{cl}}= 35.7-0.028(\mathrm{M}-\mathrm{W}) \\
&-0.155 \mathrm{I}_{\mathrm{cl}}\left[3.96 \times 10^{-3} \mathrm{fcl}\left[\left(\mathrm{T}_{\mathrm{cl}}+273\right)^{4}\right.\right. \\
&\left.-\left(\mathrm{T}_{\mathrm{mrt}}+273\right)^{4}\right]- \text { fcl.hc }\left(\mathrm{T}_{\mathrm{cl}}-\mathrm{T}_{\mathrm{a}}\right) \\
& \mathrm{h}_{\mathrm{c}}=\left\{\begin{array}{l}
2.38\left(\mathrm{~T}_{\mathrm{cl}}-\mathrm{T}_{\mathrm{a}}\right)^{0.25} \text { for } 2.38\left(\mathrm{~T}_{\mathrm{cl}}+\mathrm{T}_{\mathrm{a}}\right)^{0.25} \geq 12.1 \sqrt{\mathrm{V}_{\text {air }}} \\
12.1 \sqrt{\mathrm{V}_{\mathrm{air}}} \text { for } 2.38\left(\mathrm{~T}_{\mathrm{cl}}-\mathrm{T}_{\mathrm{a}}\right)^{0.25} \leq 12.1 \sqrt{\mathrm{V}_{\text {air }}}
\end{array}\right.
\end{aligned}
$$

The parameters are defined as follows:

$\mathrm{PMV}=$ Predicted mean vote

$\mathrm{M}=\operatorname{Metabolism}\left(\mathrm{W} \mathrm{m}^{-2}\right)$

$\mathrm{W}=$ External work, equal to zero for most activity $\left(\mathrm{W} \mathrm{m} \mathrm{m}^{-2}\right)$

$\mathrm{I}_{\mathrm{cl}} \quad=$ Thermal resistance of Clothing (Clo)

$\mathrm{f}_{\mathrm{cl}} \quad=$ Ratio of body's surface area when fully clothed to body's surface area when nude

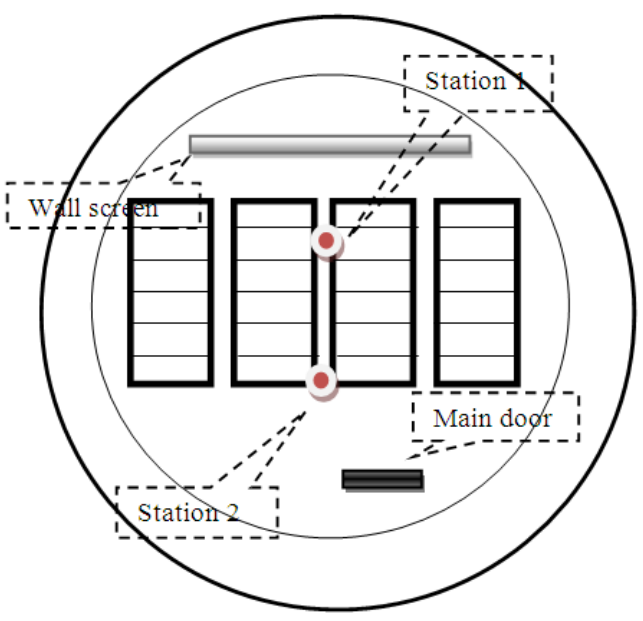

Fig. 1: The layout of the selected call centre 
$\mathrm{T}_{\mathrm{a}} \quad=$ Air temperature $\left({ }^{\circ} \mathrm{C}\right)$

$\mathrm{T}_{\text {mrt }}=$ Mean radiant temperature $\left({ }^{\circ} \mathrm{C}\right)$

$\mathrm{V}_{\text {air }} \quad=$ Relative air velocity $\left(\mathrm{m} \mathrm{sec}^{-1}\right)$

$\mathrm{Pa}=$ Partial water vapor Pressure $(\mathrm{Pa})$

$\mathrm{h}_{\mathrm{c}} \quad=$ Convectional heat transfer coefficient $\left(\mathrm{W} \mathrm{m}{ }^{-2} \mathrm{~K}\right)$

$\mathrm{T}_{\mathrm{cl}} \quad=$ Surface temperature of clothing $\left({ }^{\circ} \mathrm{C}\right)$ Eq. 4:

Furthermore, the equation for PPD is given by

Predicted Percentage Dissatisfied (PPD) is used to estimate the thermal comfort satisfaction of the occupant. It is considered that satisfying 80 of occupant is good: that is, PPD less than $20 \%$ is good (Guan et al., 2003).

Improving workers' productivity, occupational health and safety are major concerns of industry, especially in developing countries. However, these industries are featured with improper workplace design, ill-structured jobs, mismatch between workers' abilities and job demands, adverse environment, poor humanmachine system design and inappropriate management programs (Freire et al., 2008). Light, noise, air quality and the thermal environment were considered factors that would influence the acceptability and performance on the occupants of premises. International Organization for Standardization (1994) stated that lower emotional health is manifested as psychological distress, depression and anxiety, whereas lower physical health is manifested as heart disease, insomnia, headaches and infections. These health problems could lead to organizational symptoms such as job dissatisfaction, absenteeism and poor work quality. Irritated, sore eyes and throat, hoarseness, stuffy congested nose, excessive mental fatigue, headache and unusual tiredness were all signs of the negative workplace environmental conditions (Fanger, 1970).

\section{MATERIALS AND METHODS}

Experiments set up: The measurement using thermal comfort instrument as illustrated in Fig. 2 that located in the specified work space. Two lines in same production were selected in different location in line production of handling trouble report in call centre, network operation in TM as shown in Fig. 1. One of the line production selected was near the wall screen that factors of thermal comfort include illumination suspected will be affected

to the result of production in the line. The other line production selected is near the door and factor thermal comfort also affected to the result of the productivity. Each of the line consists of 5 operators that doing the same job. Figure 3 was shown workers handling the task during measurement in the station 1 . Figure 4 shows the equipments involved in handling the task. The main equipments were telephone and computer.

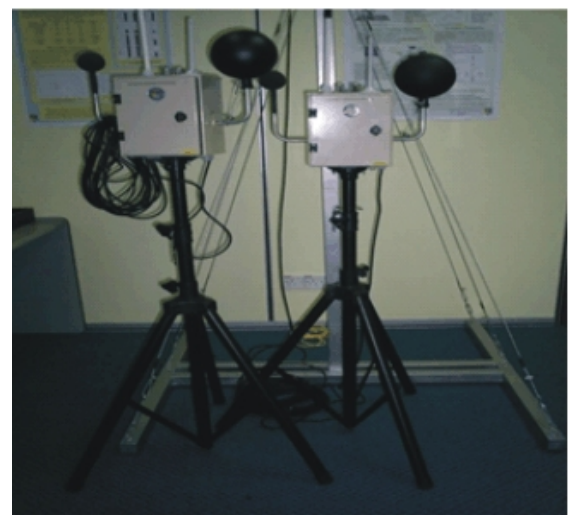

Fig. 2: Thermal comfort instrument in work place

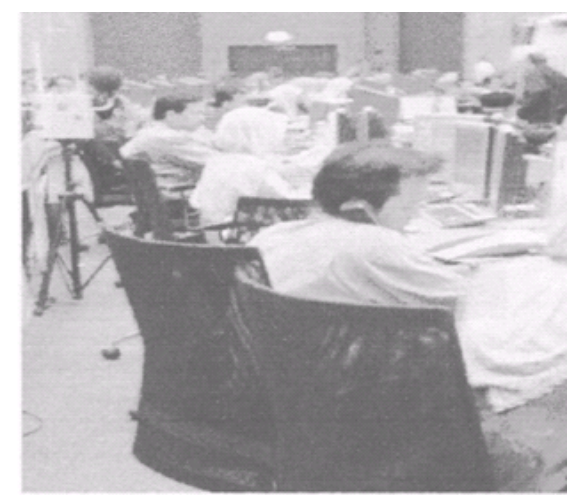

Fig. 3: Operator handling the task during

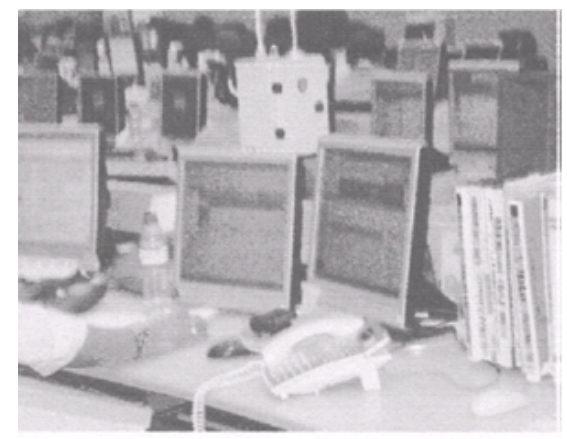

Fig. 4: Equipments involved in handling the task 
Figure 5 illustrated the production line at the station 2 . As shown in Fig. 6 the workers during handling the task at the station 2 .

Work schedule: The tasks for handling trouble report were handling by 5 operators in one period of shifts. It consists of 3 shifts per day. The details are below:

Cycle time: Morning shift (8.00 am to $3.00 \mathrm{pm})$ Afternoon shift (3.00 pm to $10.00 \mathrm{pm}$ ) Night shift (10.00 pm to $8.00 \mathrm{am})$

Numbers of operator involved in same production line -30 operators (17 male and 13 female) are shown in Table 1.

Jobs description: The task involved in this procedure:

- To check on circuit status-on the data flow, as and when there are circuit changes or reactivate activities on the circuit done by respective operators

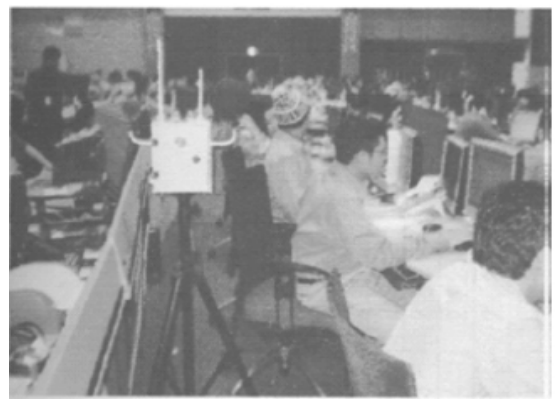

Fig. 5: Production line

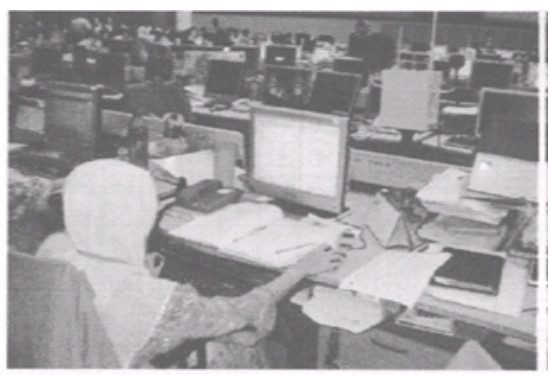

Fig. 6: Operator during handling the task

Table 1: Number of operator involved in production line

\begin{tabular}{llll}
\hline Line & Age & Male & Female \\
\hline 1 & $20-25$ & 2 & 2 \\
& $26-30$ & 4 & 1 \\
& $31-40$ & 4 & 2 \\
2 & $20-25$ & 1 & 1 \\
& $26-30$ & 3 & 4 \\
& $31-40$ & 3 & 3 \\
\hline
\end{tabular}

- $\quad$ To check and monitor on Alarm status-upon fault complaint (reactive) or during proactive monitoring

- To perform software run test upon request from customer by using network management system terminal

- To provide and check for historical alarm for the circuits reported

- $\quad$ To perform run test on the circuit and provide test result using network management software system

- $\quad$ To perform end to end test result using network management software system

\section{RESULTS AND DISCUSSION}

In this study the collected data was discussed. Thermal comfort and illuminance are examined, with exploration of the physical parameters such as air temperature, wind speed, humidity and illuminance. The develop PMV were used to analyze the relationship thermal comfort in two station selected. All these data are correlated with the results of the assessment of thermal comfort and health as perceived by the occupants. The air temperature in the two stations was increasing during the day. As shown in Fig. 7, the temperature in station 2 was higher than station 1 . The higher air temperature at the station 2 was $27.3^{\circ} \mathrm{C}$ and station 1 was $24.5^{\circ} \mathrm{C}$. A small drop can be noticed during the time of the first break. It can be seen clearly in Fig. 7. These stations were operated by workers, wearing shirts with short sleeves, trousers, socks, shoes, underpants and the work was only rated as sedentary activity (office). The according values are 1.2 met and 1.0 Clo. Hence the metabolic rate is $70 \mathrm{~W} \mathrm{~m}^{-2}$.

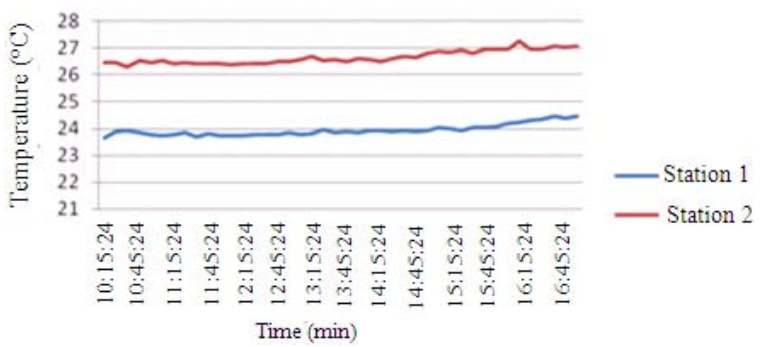

Fig. 7: Air temperature measured at the workplace

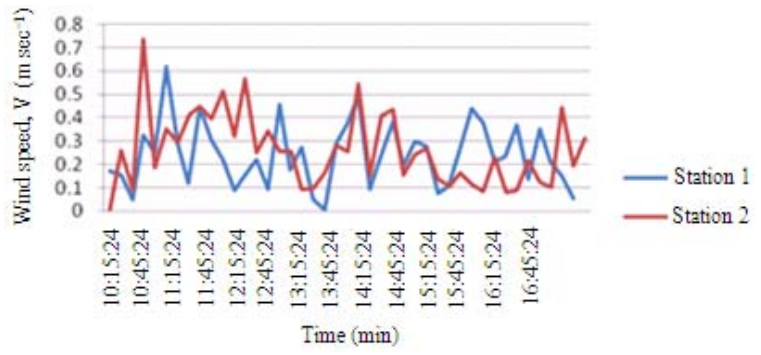

Fig. 8: Wind Speed measured at the workplace 405 
From the Fig. 8 the winds speed at station 2 higher than the station 1 . From this data at the station 2, at $11.05 \mathrm{am}$ wind speed was $0.6 \mathrm{~m} \mathrm{sec}^{-1}$ and at the same time the wind speed at station 1 was $0.3 \mathrm{~m} \mathrm{sec}^{-1}$. After lunch break, the wind speed increase again at both station. Further analysis showed that the wind speed decreases in both station at $3.00 \mathrm{pm}$. It was due to transition shift between mornings to afternoon. At $3.20 \mathrm{pm}$ the wind speed rose up and at $5.00 \mathrm{pm}$.

It can be seen from the graph in Fig. 9, the humidity curve is the inverse of the temperature curve. What is interesting in Fig. 9 were the both humidity decreases consistent. Starting with values of around $63 \%$ relative humidity, the tendency is decreasing.

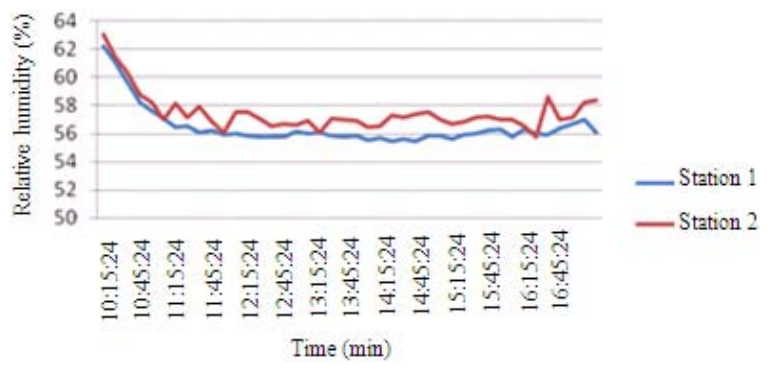

Fig. 9: Relative Humidity measured at the workplace

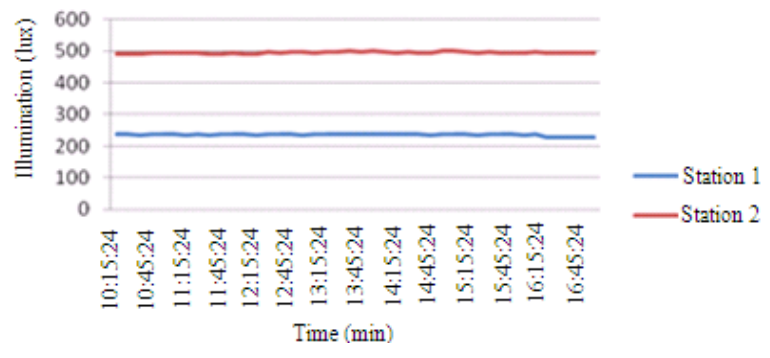

Fig. 10: Illumination measured at the workplace

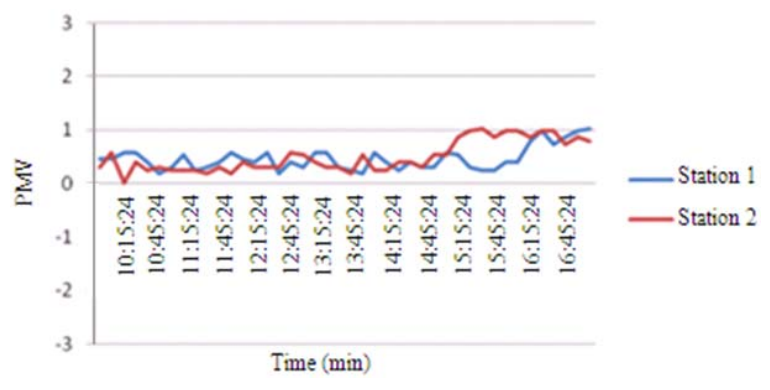

Fig. 11: Comparison PMV in two station at the workplace
During the time of the lunch break a little bump is visible in the graph. Before this, the humidity decreased to values around $57 \%$. The difference is not much, but noticeable. At 3:30 pm the humidity decreased again to $55 \%$ and during measurement finish the humidity climbed up to values of $58 \%$. The illuminance shows some special behaviors too. As shown in Fig. 10, both data illuminance were almost constant from start until finish measurement around values 236 lux for station 1 and 500 lux for station 2. They have provided a constant illumination. The values illuminace decrease at the $16.15 \mathrm{pm}$ until the measurement finish.

The day measurement started sunny and dry. However, the influence of the outside environment is stronger. Figure 11 shows the PMV index in Call Centre between two stations. The result illustrated the both station PMV index were 1.03 higher. So, scale for sensation vote towards thermal comfort was slightly warm for both stations. The PMV value at beginning measurement was around 0.5 both station. Further analysis showed at the afternoon the PMV value increases until the measurement was finish. Meanwhile, the PPD is $27.4 \%$.

As mentioned in the materials and methods, the placed selected station 1 was near the wide screen, center of workplace; however station 2 was near the main door. The results of the study show temperature at the station 1 was low than station 2. It is because the location was far away from main close, which had again a huge influence to the environmental factors. Another possible explanation for this is that, less wind speed comes in to station 1 . Other possible explanation was humidity was also decreases percentage until finish the measurement. This condition was different with station 2. The temperature at this station higher and at the same time the wind speed also more than station 1 . Furthermore, this station near the main door and the occupant was not too much here. So, not heat from occupant here. The reason temperature increase here because influence the environment outside and probable therefore that the worker come in and out. Compared to station 1, although this workplace was closed ventilated means using air-conditioned, station 1 possible obtain the heat only from the occupant. It is possible this station was around the occupant. An implication of this is the possibility that the workers have to wear shirts with short sleeves, shoes, shock, trouser and underpants. Although the temperature level at this specific day was not so high, the workers feel much affected of the temperature. The clothes and activity might be a reason for stronger impression of the temperature. The humidity is, compared to other stations more affecting. The reason might be the stronger influence of the outside environment. 


\section{CONCLUSION}

Returning to the aim posed at the beginning of this study, it is now possible to state that scale for sensation vote for PMV was slightly warm that was 1.03. The following conclusions can be drawn from the present study that $72.6 \%$ are likely to be satisfied by the occupant in the Call Centre. This study was shown that this place was comfort for occupant. Even though the temperature at the station 1 is low but this situation could be cover by activity and clothing from occupant. An implication of this is the possibility that the thermal comfort of a factory worker depends on there being an average skin temperature (resulting from the combination of climate, clothing and metabolic heat production). The purpose of heating or cooling enclosures to be occupied by human being is to provide thermal comfort. A given system will be judged by the occupants according to its ability to satisfy this demand and it is therefore obvious that a rational calculation of heating and air-conditioning systems must begin with the conditions for comfort. The activity level and the thermal resistance of clothing are determined, depending on the purpose for which the space will be used and the comfort equation gives all combinations of the environmental variables which will create optimal thermal comfort. Therefore there are many possibilities for satisfying the comfort demand. However, for a given room, the environmental system chosen, the thermal properties of the room and the outdoor conditions will jointly establish certain dependence between the variables. Clearly it is important to ensure that the level of dissatisfaction with the thermal environment is kept to minimum, preferably to no more than $5 \%$ of the people populating a building.

\section{REFERENCES}

American Society of Heating, 2005. Refrigerating and Air-Conditioning, ASHRAE HandbookFundamentals. Refrigerating and Air- Conditioning Engineers, Inc., Atlanta, ISBN: 1931862710.

Chun, C., A. Kwok, T. Mitamura, N. Miwa and A. Tamura, 2008. Thermal diary: Connecting temperature history to indoor comfort. Build. Environ., 43: 877-885. DOI: 10.1016/j.buildenv.2007.01.031

Fanger, P.O., 1970. Thermal Comfort: Analysis and Applications in Environmental Engineering. Danish Technical Press, Copenhagen, ISBN: 0-07019915-9, pp: 244.

Feriadi, H., N.H. Wong, S. Chandra and K.W. Cheong, 2003. Adaptive behavior and thermal comfort in Singapore's naturally ventilated housing. Build. Res. Inform., 31: 13-23.
Goto, T., J. Toftum, R. De Dear and P.O. Fanger, 2002. Thermal sensation and comfort with transient metabolic rates. Proceeding of the 9th International Conference on Indoor Air Quality and Climate, June 30-July 5, Santa Cruz, California, pp: 1038-1043. http://www.irb.fraunhofer.de/bauforschung/baufolit .jsp?lang=en\&s=CIB6491.pdf

Guan, Y., M.H. Hosni, B.W. Jones and T.P. Gielda, 2003. Literature review of the advances in thermal comfort modeling. ASHRAE Trans.- Am. Soc. Heat. Refrigerat. Air Condition. Eng., 109: 908-916. http://www.lancs.ac.uk/fass/projects/futcom/fc_litfi nal1.pdf

Ho, S.H., L. Rosario and M.M. Rahman, 2008. Thermal comfort enhancement by using a ceiling fan. Applied Therm. Eng., 29: 1648-1656. DOI: 10.1016/j.applthermaleng.2008.07.015

Holmes, M.J. and J.N. Hacker, 2007. Climate change, thermal comfort and energy: Meeting the design challenges of the 21st century. Energy Build., 39: 802-814. DOI: 10.1016/j.enbuild.2007.02.009

Ibrahim, A., O. Kaynakli and A. Yigit, 2007. Effects of radiant temperature on thermal comfort. Build. Environ., 42: 3210-3220. DOI: 10.1016/j.buildenv.2006.08.009

International Organization for Standardization, 1994. Moderate thermal environments-Determination of the PMV and PPD indices and specification of the conditions for thermal comfort. ISO 7730 . http://www.iso.org/iso/catalogue_detail.htm?csnum ber $=14567$

Morgan, C.A., R.J. de Dear and G.S. Brager, 2002. Climate, clothing and adaptation in the built environment. Proceedings of the 9th International Conference on Indoor Air Quality and Climate, June 30-July 5, Monterey, California , pp: 98-103. http://d.wanfangdata.com.cn/NSTLHY_NSTL_HY 196149.aspx

Freire, R.Z., G.H.C. Oliveira and N. Mendes, 2008. Predictive controllers for thermal comfort optimization and energy savings. Energy Build., 40: 1353-1365. DOI: 10.1016/j.enbuild.2007.12.007

Shek, K.W. and W.T. Chan, 2008. Combined comfort model of thermal comfort and air quality on buses in Hong Kong. Sci. Total Environ., 389: 277-282. PMID: 17949792

Taylor, P., R.J. Fuller and M.B. Luther, 2008. Energy use and thermal comfort in a rammed earth office building. Energy Build., 40: 793-800. DOI: 10.1016/j.enbuild.2007.05.013 